\title{
Connexin 43 Affects Osteogenic Differentiation of the Posterior Longitudinal Ligament Cells via Regulation of ERK Activity by Stabilizing Runx2 in Ossification
}

\author{
Haisong Yang Lei Shi Guodong Shi Yongfei Guo Dechun Chen Deyu Chen \\ Jiangang Shi
}

Department of Orthopedics, Changzheng Hospital, Shanghai, China

\section{Key Words}

Connexin $43 \cdot$ ERK $•$ Ossification • Posterior longitudinal ligament $•$ Dexamethasone $\cdot$ Runx2

\begin{abstract}
Aims: Connexin 43 is one of the most potent gap junction proteins related to osteoblast differentiation and bone formation. We hypothesized that Connexin 43 is a significant factor in osteogenic differentiation in the posterior longitudinal ligament through the regulation of extracellular signal-regulated kinases (ERK) activity by converging on Runt-related transcription factor 2 (Runx2) activity. In this study, we mapped the activity of Connexin 43 to ERK and Runx2 by extracting longitudinal ligament cell for culture and silencing Connexin expression in addition to dexamethasone treatment in vitro. Methods: qRT-PCR, Western Blot, and Runx2-responsive Luciferase Reporter Assay were performed to detect the activity of ERK, Runx2 and the expression levels of osseous genes under Connexin 43 modification. Results: Downregulation of Connexin 43 resulted in suppression of dexamethasone-induced osteogenic differentiation, inhibition of the ERK and Runx2 activity, and reduction of osseous gene expression. Conclusion: these data support that Connexin 43 significantly regulates osteogenic differentiation in the cells from posterior longitudinal ligament by altering the activity of ERK, and subsequently causing the modification of Runx2.
\end{abstract}

Copyright (C) 2016 S. Karger AG, Basel

\section{Introduction}

Ossification of the posterior longitudinal ligament (OPLL) is a pathological condition causing ectopic bone formation in the cervical spinal ligament [1]. Although many local factors $\mathrm{H}$. Yang and L. Shi contributed equally to this work.

\begin{tabular}{ll}
\hline Deyu Chen and Jiangang Shi & Department of Orthopedics, Changzheng Hospital, No. 415, Fengyang Road, Shanghai \\
& 200003, (China) \\
E-Mail chengspine@126.com and shijgxhz@126.com
\end{tabular}




\section{Cellular Physiology Cell Physiol Biochem 2016;38:237-247

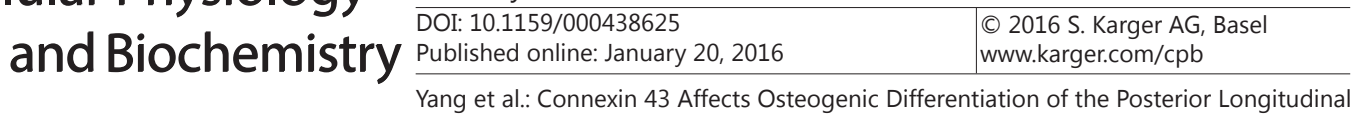 Ligament Cells}

have been proposed, some of which have been confirmed during OPLL development, studies have investigated the osteogenesis of fibroblasts from ossified ligaments [2]. The mechanism of cellular signaling transduction regarding OPLL remains unclear. An association of OPLL was reported as early as 1839. OPLL is a common disease throughout China and Asia [3].

Gap junctions are channels that are formed by hexamers of connexins (called a hemichannel or connexon), which connect across the intercellular space [4]. The resultant gap junction forms an aqueous pore between the cytoplasm of two cells that permits the direct exchange of ions, small molecules and second messengers intercellularly $[4,5]$. In bone, gap junctions primarily composed of Connexin 43 interconnect osteoblasts and osteocytes [6]. In osteoblasts and osteocytes, Connexin 43 plays an important role in the transmission of hormone, mechanical load and the signaling induction by growth factors [7, 8]. The growth factors induced signals affect the quality and geometry of the bones through the hemi channel activity or the gap junctions during cell-to cell communications. However, the mechanism of how Connexin 43 regulates the gene expression in the bones is not clear during OPLL development.

Some studies have shown that Connexin 43 is an essential factor in osteogenesis and osteoblast function [9]. Furthermore, studies have shown the correlative function of Connexin 43 in modification of ERK activity, which consequently regulates Runx2 [10]. Runx2 is an essential transcription factor for osteoblast differentiation [11],and also involved in chondrocyte maturation [12]. Therefore, it would be crucial to further assess the correlation of Connexin 43 with Runx2 through the regulation of ERK activity.

In order to gain insight of how Connexin 43 regulates osteoblast function, this study aims to further determine the functional relevance between Connexin 43, ERK, and Runx2. Specifically, we utilized RNA interference (RNAi) to target Connexin 43 in OPLL cells and then we detected the expression changes in the messenger RNA (mRNA) of osteoblastspecific genes of osteocalcin (OCN), alkaline phosphatase(ALP), and type I collagen (COL I) post transfection. Furthermore, we detected ERK and Runx2 protein via Western Blot and Luciferase Reporter Assay.

\section{Materials and Methods}

\section{Hematoxylin and Eosin Stain}

Human tissue samples of OPLL and non-OPLL patients were removed in one block and fixed with $4 \%$ paraformaldehyde at $4^{\circ} \mathrm{C}$. After fixation, the tissues were decalcified with $0.46 \mathrm{M}$ ethylenediaminetetraacetic acid solution for three weeks. Subsequently, the tissue samples were cut, divided, and processed through a graded series of ethanol and xylene solutions for embedding in paraffin. The $5 \mathrm{~mm}$-thick sections were prepared in a mid-sagittal plane and were then subjected to staining by Hematoxylin and Eosin Stain (H\&E). The cell plates were stained with Alizarin Red S for observation of mineralization nodules. All samples were observed under a light microscope.

\section{Cell Culture and toludine blue staining}

Thirty-eight posterior longitudinal ligament specimens from 20 OPLL patients and 18 non-OPLL patients were obtained. The ligaments were isolated carefully from a non-ossified site to avoid any possible contamination with osteogenic cells. Afterwards, they were minced into approximately $0.5 \mathrm{~mm} 3$ pieces and washed with phosphate-buffered saline (PBS) twice. The ligament fragments were then plated in $90 \mathrm{~mm}$ culture dishes and maintained in low glucose Dulbecco Modified Eagle Medium (DMEM) supplemented with $10 \%$ fetal bovine serum. The explants were incubated in a humidified atmosphere of $95 \%$ air and $5 \%$ $\mathrm{CO}_{2}$ at $37^{\circ} \mathrm{C}$. Cells derived from the explants were harvested from the cultured dishes with $0.05 \%$ trypsin for further experimentation. Inverted phase contrast microscopy was used to observe the cell morphology. Cells after treatment were washed with PBS twice, fixed in 95\% ethanol, and then stained with toluidine blue [13].

\section{KARGER}




\section{Cellular Physiology Cell Physiol Biochem 2016;38:237-247

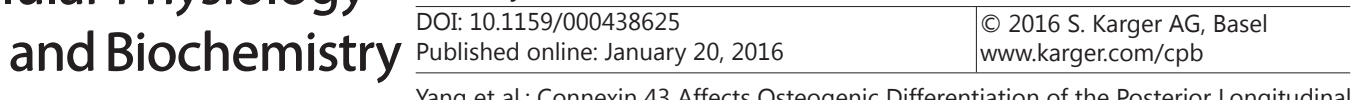 \\ Yang et al.: Connexin 43 Affects Osteogenic Differentiation of the Posterior Longitudinal Ligament Cells}

Real-time quantitative RT-PCR

Total RNA was extracted from tissues and cultured cell lines using the TRIzol Reagent (Invitiogen, China) and reverse transcribed into cDNA using the PrimeScript reverse transcription-PCR (RT-PCR) kit (TaKaRa,Japan). Real-time PCR was performed using SYBR Premix Ex TaqTM II kit (TaKaRa) according to the manufacturer's protocol on an MX3005P QPCR system (Stratagene, La Jolla, CA, USA). PCR mixtures were initially heated at $95^{\circ} \mathrm{C}$ for $10 \mathrm{~s}$, and then at $95^{\circ} \mathrm{C}$ for $30 \mathrm{~s}, 58^{\circ} \mathrm{C}$ for $30 \mathrm{~s}$ and $72^{\circ} \mathrm{C}$ for $40 \mathrm{~s}$ for 40 cycles. The glyceraldehyde- 3-phosphate dehydrogenase (GAPDH) mRNA was used as internal control. The primers designed for quantitative real-time RT-PCR analysis were as follows: OCN forward primer 5'-AGG GCA GCG AGG TAG TGA-3', OCN reverse primer 5'-CCT GAA AGC CGA TGT GGT-3'. ALP forward primer 5'-GTG GAC TAT GCT CAC AACAA-3', ALP reverse primer 5'-GGA GAA ATA CGT TCG CTAGA-3'. COL I forward primer 5‘CGA AGA CAT CCC ACC AATC-3', COL I reverse primer 5'-ATC ACG TCA TCG CAC AACA-3'. GAPDH forward primer 5'-CGC GGG CTC CAG AAC ATCAT-3', GAPDH reverse primer 5'-CCA GCC CCA GCG TCA AAG GTG-3’. All primers above were synthesized by Shanghai Sangon Biological Engineering Technology and Services Co., Ltd. (Shanghai, China). All of the reactions were run in triplicates. The delta-Ct method for relative quantification of gene expression was used to determine mRNA expression levels.

\section{Western Blot}

Whole cell extracts were extracted and subjected to Western blots. Equal amount of protein $(20 \mu \mathrm{g} /$ well) from each sample was separated on a $10 \%$ sodium dodecyl sulfate polyacrylamide gel. The proteins were transferred from the gel to a nitrocellulose membrane and then were blocked in 5\% nonfat dried milk for 1 hour at room temperature in Tris-Buffered Saline with Tween-20 (TBST) buffer (Ximei Chem Co Ltd, Shanghai, CHN). Blots were then probed overnight at ${ }^{\circ}{ }^{\circ} \mathrm{C}$ with anti-Connexin 43 (rabbit, Sigma Aldrich Co, St Louis, MO) at a 1:500 dilution. The membranes were then washed and incubated with a goat anti-rabbit Immunoglobulin G (IgG) (H+L) linked to horseradish peroxidase (1:1000) for 2 hours at room temperature. Thereafter, bound antibody was revealed using 3, 3-diaminobenzidine as the substrate. Finally, the membranes were dried and scanned using an Epson Perfection photo scanner (Epson Corporation, CA, USA). Protein intensities were quantitatively analyzed by Quantity One software (Bio-Rad). GAPDH was used as the internal control. The value of Connexin 43 protein expression was the ratio of Connexin 43 per GAPDH. Each specimen was performed at least three times.

\section{Short Interfering RNA (siRNA) Construction and Transfection}

The Connexin43-specific small interfering sequence was chemically synthesized as follows: positive sense strand 5'-GAU GAU AAC CAG AAU UCU ATT-3', antisense strand 5'-UAG AAU UCU GGU UAU CAU CGG3'. Nonsense siRNA were used as a negative control with the following sequence: positive sense strand 5'-UUCUCCGAACGUGUCACGUTT-3', antisense strand 5'-ACG UGA CAC GUU CGG AGA ATT-3'. The siRNAs were synthesized in duplex by GenePharma Co, (Shanghai, China) and transfected into the posterior longitudinal ligament cells via Lipofectamine 2000. Transfection of siRNA was performed according to the manufacturer's instruction. These cells were treated with dexamethasone for 72 hours and then subjected to evaluation. Experiments were repeated at least three times in triplicates. Data from representative experiments are shown.

\section{Luciferase Reporter Assays}

Luciferase reporter assays were performed as described previously [14]. All experiments were repeated a minimum of three times in triplicates. Data from representative experiments are shown. Luciferase data shown on a single graph was from the same experiment so that all other variables were kept constant.

\section{Statistical Analysis}

Data are expressed as mean \pm SD. Data analysis was conducted using independent sample $t$ tests. The difference was analyzed using a paired t test. All analyses were performed with the Statistical Package for Social Sciences (SPSS version 6.1.1, Norusis SPSS Inc, Chicago, IL) software in a two-tailed fashion with a level of significance of $\mathrm{p}<0.05$. 


\section{Cellular Physiology Cell Physiol Biochem 2016;38:237-247

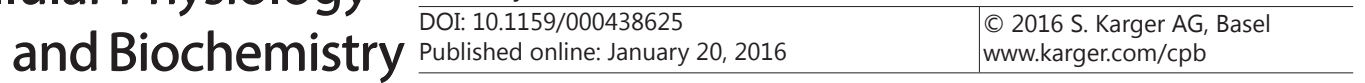 \\ Yang et al.: Connexin 43 Affects Osteogenic Differentiation of the Posterior Longitudinal Ligament Cells}

\section{Results}

Tissue derived from OPLL carries osteogenic characteristics

In order to identify the specific structure, main components, and morphological differences between OPLL tissue and non-ossified tissue, H\&E method was used. Histological evaluation revealed that ectopic formation of bone tissue was identified from a sample taken from an ossified posterior longitudinal ligament tissue with a proliferation of mature osteoblast-like cell (arrows $\searrow$ ) as compared with non-ossified tissues (Fig. 1A).

To clarify whether the tissue derived from OPLL has osteogenic characteristics, three osteoblast specific genes including OCN, ALP, and COL I were detected and compared with those in non-OPLL tissue via RT-PCR and Western blot. mRNA and protein expression of OCN, ALP, and COL1 were increased in OPLL tissue $(p<0.01)$, suggesting that the tissue derived from OPLL had an osteogenic characteristic (Fig. 1B and 1C).

\section{Dexamethasone induces ossification of posterior longitudinal ligament cells}

It has been reported that dexamethasone can induce osteogenic differentiation in human periodontal ligament cells [14-16]. To assess the dexamethasone-induced posterior longitudinal ligament cells, histochemical analysis was performed. In comparison to normal tissue samples from a posterior longitudinal ligament, histological findings showed that 100 $\mathrm{nM}$ of the glucocorticoid drug, dexamethasone, can induce proliferation in mature osteoblastlike cells from the posterior longitudinal ligament cells (Fig. 2A).

The expression of osteoblast-specific genes was also assessed by RT-PCR and Western Blot (Fig. 2B and 2C, 2D). In comparison to normal tissue samples from posterior longitudinal ligaments, the mRNA and protein expression of osteoblast-specific genes, OCN, ALP, and COL1, were significantly increased in the dexamethasone-induced posterior longitudinal

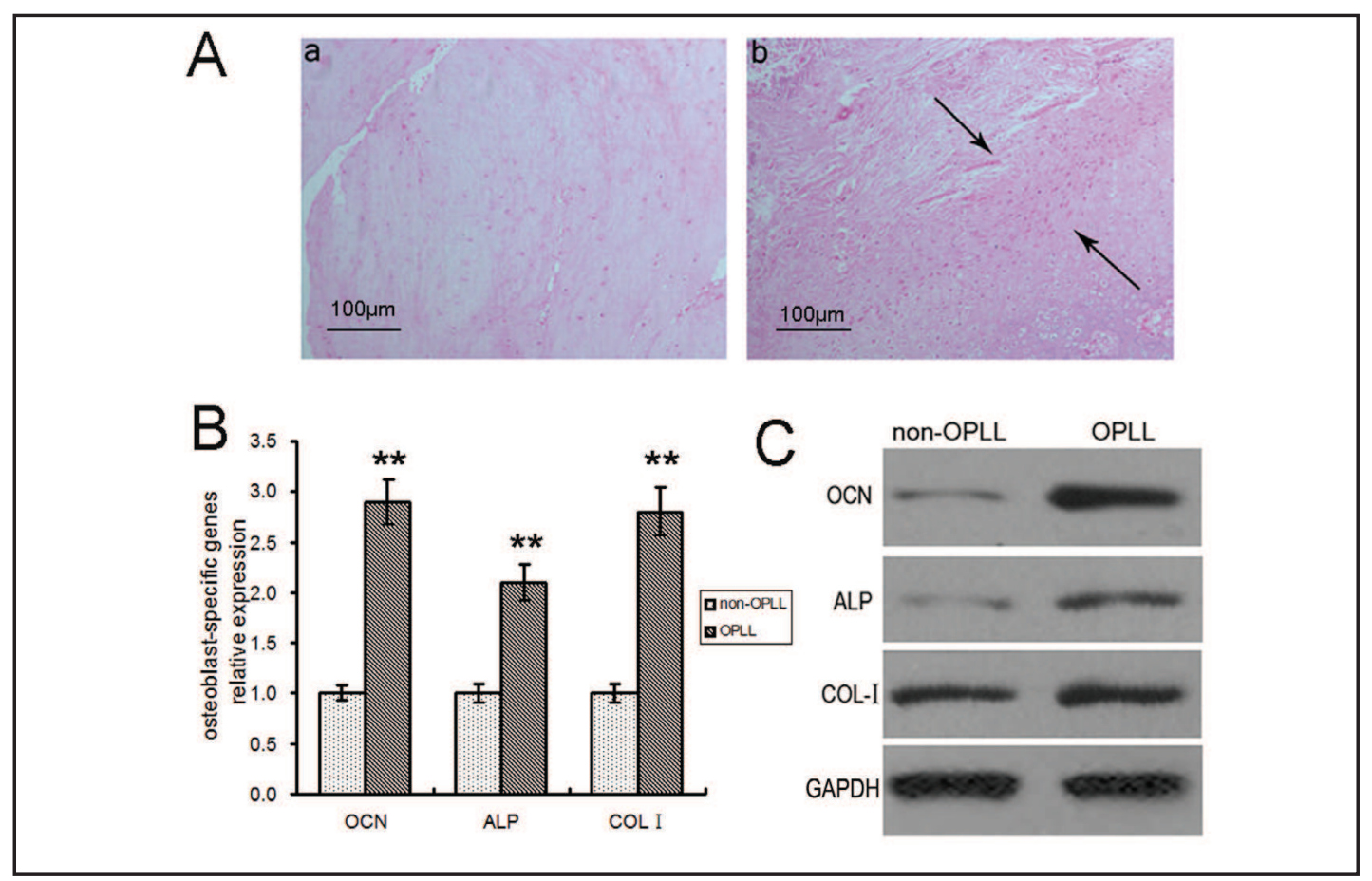

Fig. 1. The difference between ossification of posterior longitudinal ligament (OPLL) tissue and non-ossification tissue (NOPLL). (A) ectopic formation of bone tissue in ossification of posterior longitudinal ligament tissue $(\mathrm{Ab})$ with a proliferation of mature Osteoblast-like cells (HE). (B, C) The mRNA and protein expression of OCN, ALP, COL1 were increased in OPLL $(\mathrm{P}<0.01)$. 


\section{Cellular Physiology \\ Cell Physiol Biochem 2016;38:237-247 and Biochemistry \begin{tabular}{l|l}
\hline DOI: $10.1159 / 000438625$ & (C) 2016 S. Karger AG, Basel
\end{tabular} \\ Yang et al.: Connexin 43 Affects Osteogenic Differentiation of the Posterior Longitudinal Ligament Cells}

Fig. 2. The difference between the cells of OPLL treated with and without Dexamethasone. (A) ectopic formation of cartilaginous tissue were observed in Dexamethasone $(\mathrm{Ab})$ with a proliferation of mature Osteoblast-like cells (HE). (B, C, D) The mRNA and protein expression of $\mathrm{Cx} 43, \mathrm{OCN}$, ALP, COL1 were increased in Dexamethasone $(\mathrm{P}<0.01)$.

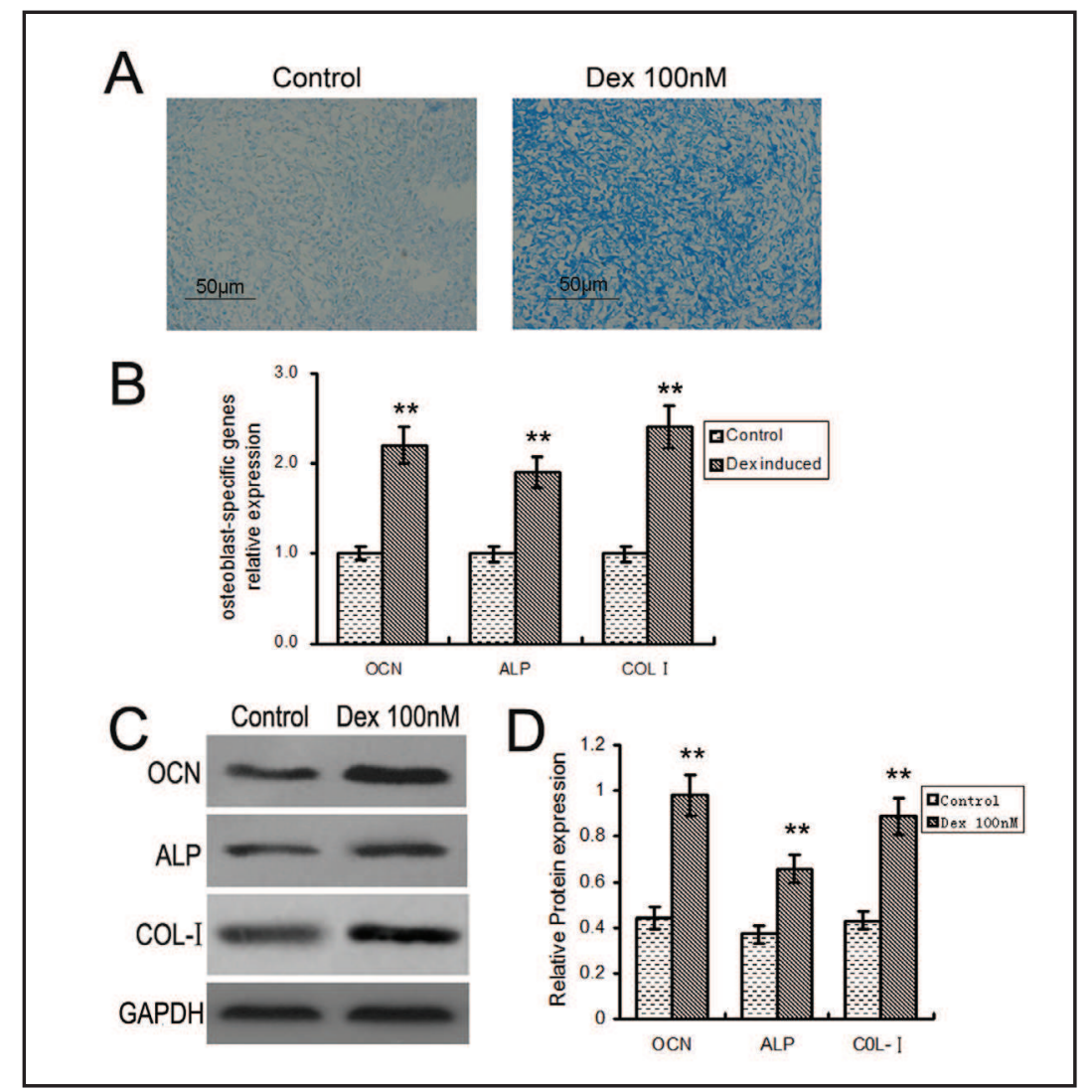

ligament $(p<0.01)$. These data indicated that dexamethasone can significantly induce the transformation of posterior longitudinal ligament cell into osteoblast-like cell.

Down regulation of connexin 43 inhibits dexamethasone-induced ossification

In order to evaluate the effect of Connexin 43 on osteogenic differentiation of the posterior longitudinal ligament cells, toluidine blue staining was performed. A significant difference among the three cell samples (dexamethasone, dexamethasone + empty vector, dexamethasone + Cx43-siRNA) can be observed (Fig. 3A). Significant ossification can be observed in dexamethasone-induced posterior longitudinal ligament cell in comparison with dexamethasone induction combined with Connexin 43-siRNA. The osteogenic differentiation of posterior longitudinal ligament cells was significantly inhibited despite the effects of dexamethasone. This result suggested that Connexin 43 is a major factor in osteogenic differentiation.

To determine the impact of time on the $\mathrm{Cx} 43$-siRNA transfection, the expression of $\mathrm{Cx} 43$ in cells was examined after the transfection with $\mathrm{Cx} 43$-siRNA in each set of experiments. The inhibition effect was the strongest at 72h (Fig. 3B). Protein and mRNA expression of Connexin 43 were detected and compared between the transfected group and the negative control. The expression of Connexin 43 in posterior longitudinal ligament cells was significantly down regulated $72 \mathrm{~h}$ after transfection with Cx43-siRNA (Fig. 3C and 3D).

The protein and mRNA expressions of OCN, ALP and COL I in posterior longitudinal ligament cells showed significant reduction $72 \mathrm{~h}$ after $\mathrm{Cx} 43$-siRNA transfection (Fig. 3C and 3D). RT-PCR analysis revealed that the ALP, OCN and COL I levels of the control group, empty vector, and Connexin 43-siRNA differed by 43\% ( $<<0.01), 48 \%(\mathrm{p}<0.01), 39 \%(\mathrm{p}<0.01)$, respectively. These results indicated that that Connexin 43 has a major impact on osteogenic differentiation despite the proliferative effect of dexamethasone. 


\section{Cellular Physiology Cell Physiol Biochem 2016;38:237-247

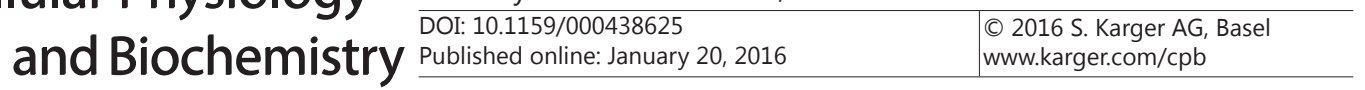 \\ Yang et al.: Connexin 43 Affects Osteogenic Differentiation of the Posterior Longitudinal Ligament Cells}

Fig. 3. Down regulation of Cx43 inhibits osteogenesis differentiation of cells of posterior longitudinal ligament when induced by Dexamethasone; (A) the difference between cell transfected with and without Cx43-siRNA when treated with Dexamethasone. (B) the effect of inhibiting the expression of $\mathrm{Cx} 43$ by $\mathrm{Cx} 43$-siRNA was affected by time. (C) the expression of Bony gene in cell of posterior longitudinal ligament transfected with and without Cx43-siRNA when treated with Dexamethasone (measured by Western Blot). (D) the expression of Bony gene in cell of posterior lon-

A
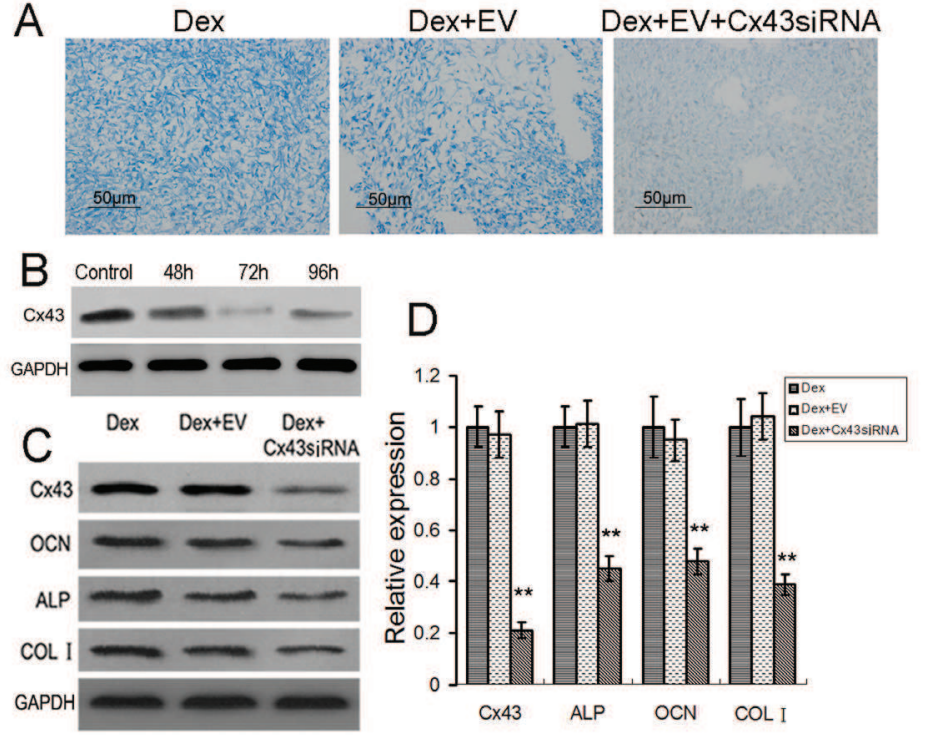

gitudinal ligament transfected with and without Cx43-siRNA treated with dexamethasone (measured by qRT-PCR).

Fig. 4. Down regulated expression of $\mathrm{Cx} 43$ inhibits pERK and reduces Runx2 activity. (A) Cells were transfected with cx43siRnA. The cells were lysed $72 \mathrm{~h}$ post-transfection. Whole cell extracts were subjected to Western blotting with anti-phospho ERK, antitotal ERK and Anti-GAPDH antibodies as load controls. (B) Densitometric quantitation of the bands is shown to the right. Representative data are shown. (C) Down regulation of $\mathrm{Cx} 43$ reduces activation of runx2 promoter luciferase (** $\mathrm{p}<0.01$ ). (D) Down regulation of $\mathrm{Cx} 43$ reduces Runx2 expression by Western blot.

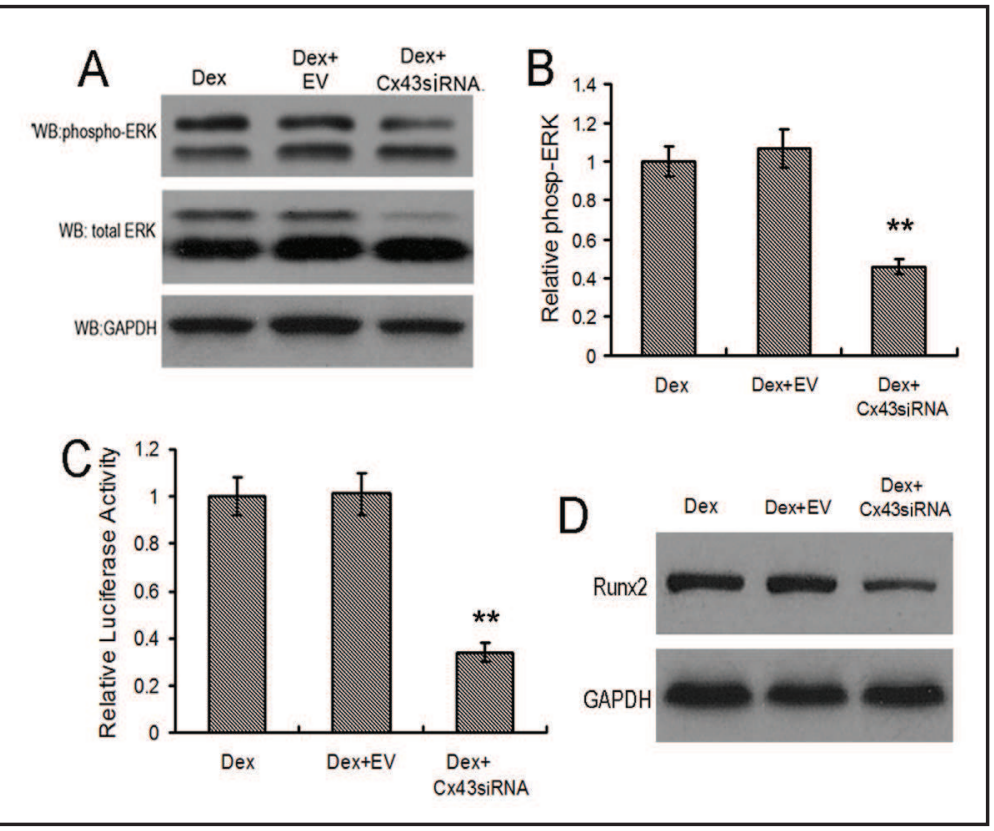

Down regulation of connexin 43 inhibits the activation of ERK

Previous studies have demonstrated that ERK activation plays an important role in cartilage formation. In order to assess the effect of Connexin 43 on the down regulation of ERK activity and ossification formation, ERK protein levels from different treated groups as described above were detected by western blot analysis (Fig. 4A). Densitometric quantitation of the bands showed a significant down regulation of phospho-ERK activity in Connexin 43-siRNA group ( $p<0.05$ ), suggesting that the phosphorylation of ERK induced by dexamethasone was attenuated when Connexin 43 was silenced (Fig. 4B).

Based on recent studies, the expression of Connexin 43 affects the ERK signaling pathway and the transcriptional activity of Runx2. To test this hypothesis, luciferase activity of Runx2 
Fig. 5. ERK inhibitor U0126 reduced pERK. (A) ERK inhibitor U0126 reduced pERK. (B) Densitometric quantitation of the bands is shown to the right. (C) ERK inhibitor U0126 reduced Runx2 promoter luciferase. (D) ERK inhibtor U0126 reduced the expression of Bony gene.

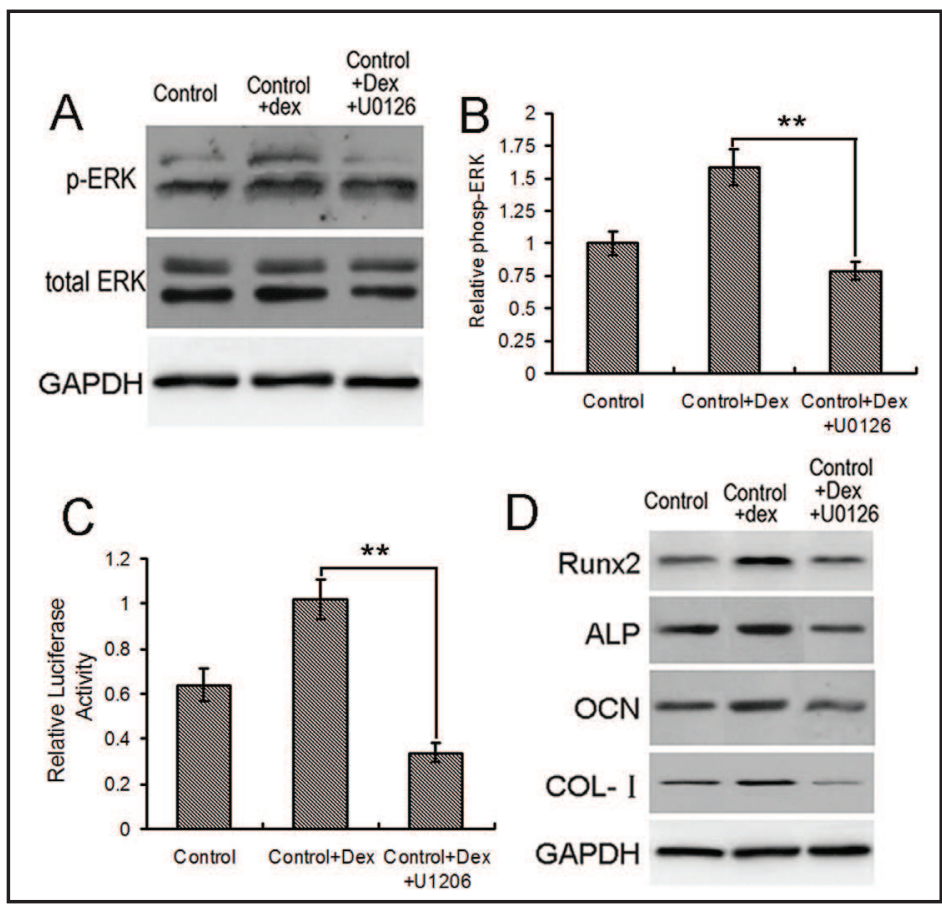

was analyzed by luciferase reporter assay. The activation of Runx2 promoter luciferase was significantly decreased when cells were induced with Connexin 43 siRNA $(p<0.05)$ (Fig. 4C).

Protein expressions of Runx2 were detected and compared between the transfected group and the negative control group. The expression of Runx2 of the posterior longitudinal ligament cell was significantly down regulated with the transfection of Cx43-siRNA (Fig. 4D).

The evidence demonstrated that Connexin 43 is correlated with Runx2 through modification of ERK activity. Silencing of Connexin 43 could potentially lead to a down regulation of ERK activity, thereby causing attenuated Runx2 activity.

Effects of ERK activity inhibition on gene expression

In order to verify whether the ERKsignaling pathway plays an importantrole in osteogenic differentiation of the posterior longitudinal ligament cells induced by dexamethasone, ERK inhibitor U-0126 was introduced to the dexamethasone-treated group. Western blot results showed that phospho-ERK protein expression was significantly inhibited by $100 \mathrm{uM} \mathrm{U-0126}$ compared with control and dexamethasone-induced alone groups $(p<0.05)$ (Fig. 5A and 5B).

For further analysis, Luciferase Reporter Assays were also performed to detect the effect of ERK on Runx2 activity. There was a significant down regulation of Runx2 promoter luciferase activity when ERK was inhibited (Fig. 5C). Western blot also showed a significant decrease in Runx2 level as well as the expression of Bony genes ALP, OCN and COL1 with the presence of the ERK inhibitor U0126 ( $p<0.05$ ) (Fig. 5D). These results further confirmed that ERK is highly affected by Runx2 activity.

\section{Discussion}

There are numerous clinical studies about the progression of OPLL under mechanical stress. OPLL cells have been transformed into cells that are highly sensitive to mechanical stress, which may induce the progression of OPLL. OPLL cells can detect and transduce mechanical stretch into biochemical signals that can modulate locomotion $[2,3]$. OPLL is highly progressed in both longitudinal direction and thickness after posterior decompressive surgery, regardless of the ossification type [17]. The progression of OPLL is highly correlated 


\section{Cellular Physiology Cell Physiol Biochem 2016;38:237-247 \\ \begin{tabular}{ll|l}
\cline { 2 - 2 } and Biochemistry & DOI: 10.1159/000438625 & $\begin{array}{l}\text { C } 2016 \mathrm{~S} . \text { Karger AG, Basel } \\
\text { www.karger.com/cpb }\end{array}$ \\
\cline { 2 - 3 } Yang et al.: Connexin 43 Affects Osteogenic Differentiation of the Posterior Longitudinal
\end{tabular} Ligament Cells}

with abnormal strain distribution in the intervertebral discs and is frequently observed when strain in the tensile direction is distributed over the disc [2]. The ossification tends to progress in patients with high mobility, in these patients, the range of motion of the cervical spine was severely limited, indicating that dynamic factors were important in the development of OPLL [3].

Additionally, gene analysis has been applied to clarify the underlying genetic background due to the high prevalence of OPLL. Histochemical studies of OPLL have demonstrated certain characteristics, including the presence of several different phenotypic osteoblasts in ligament cells obtained from non-ossified sites, ALP activity, parathyroid hormoneand prostaglandin E2-stimulated increases in cAMP, and responses to calcification and 1,25-dihydroxycholecalcifenol $[3,18,19]$. In addition to these systemic predispositions, multiple local factors have been proposed for the pathogenesis of OPLL. However, the specific cause at the cellular level of OPLL has not yet been found. This led to a further study on a few possible cellular targets that could potentially be helpful for therapeutic intervention regarding OPLL.

Over the past two decades, it has become clear that Connexin 43 is important for the function of osteoblasts and osteocytes $[6-9,20,21]$. This connexin contributes to the acquisition of peak bone mass and it is a major modulator of cortical modeling. Current knowledge demonstrates that Connexin 43 is more than a passive channel. Rather, it actively participates in the generation and modulation of cellular signals driving skeletal development and homeostasis [7, 20-22]. Skeletal development (bone modeling) and skeletal maintenance in post-natal life (bone remodeling) require the precise coordination of the activity of several cell types including osteoprogenitor cells, osteoblasts, osteocytes, and osteoclasts. Indeed, extracellular and intracellular autocrine and paracrine signaling among these cells types are critical to both bone modeling and remodeling [23].

Osteoblasts require Connexin 43 throughout their differentiation program to modulate cortical modeling via the regulation of bone formation and endocortical bone resorption $[8,9,21]$. Understanding the molecular mechanisms by which connexins modulate skeletal homeostasis and are response to mechanical and hormonal cues will help define potential applications of gap junction modifiers to improve bone structure and a possible therapeutic intervention for certain diseases. Indeed, any intervention intend to impact the entire bone formation unit to reverse or slow down skeletal diseases will require an understanding of the intricate methods of intercellular exchange of information, such as those afforded by Connexin 43 among osteoblasts and osteocytes, for optimal efficacy.

Furthermore, the ERK pathway has been discovered to be an important pathway to be targeted for therapeutic intervention [24]. ERK activation induced by overexpression of constitutivelyactive Mitogen Activated Protein Kinases (alsoknown as MEK1) increases Runx2 transcriptional activity [25]. ERK signaling increases Runx2 stability and transcriptional activity, partly via increasing p300 protein levels and histone acetyltransferase activity and subsequently increasing Runx2 acetylation by p300 [25]. This pathway is one of the major links between the cell surface and nucleus to control diverse functions including cell proliferation, differentiation, migration, and survival [26]. The level of Runx2 in the nucleus is a critical determinant for selection of the pathway of osteoblast differentiation [27]. Thus, the suppression of Runx2 nuclear protein is likely to be important for cell differentiation.

The ability of the ERK cascade to initiate and regulate all of these effects raises the question how its specificity is determined. In order to execute all its functions, the ERK cascade is heavily regulated at several levels, mainly by different phosphatases, but also by other interacting proteins. There are given distinct mechanisms categorized in the regulatory processes, which is critical to determine the ERK cascade specifically. These mechanisms include: (a) changes in the strength and duration of the signals regulated by inhibitory componenents, including phosphatases that induce different early genes. (b) Scaffold proteins that aggregate signaling components in the cascade and facilitate the activation of the corresponding up streams and down streams effectors. (c) Subcellular localization affected by anchoring proteins, which lead to proper targeting. (d) Crosstalk among signaling 


\section{Cellular Physiology Cell Physiol Biochem 2016;38:237-247 \\ \begin{tabular}{ll|l}
\cline { 2 - 2 } and Biochemistry & DOI: 10.1159/000438625 & $\begin{array}{l}\text { C } 2016 \mathrm{~S} . \text { Karger AG, Basel } \\
\text { www.karger.com/cpb }\end{array}$ \\
\cline { 2 - 3 } Yang et al.: Connexin 43 Affects Osteogenic Differentiation of the Posterior Longitudinal
\end{tabular} Ligament Cells}

pathways modulating the activity of downstream of ERK cascade by affecting the strength of the signals. (e) The distinct functions of multiple components within the cascade tracking to specific targets [25-27]. Understanding the mechanisms of activation and the regulation of the various components of this cascade will enhance our insight into the regulation of the ERK-dependent cellular processes in normal cells or of the malfunction in various diseases and a probable therapeutic target for certain diseases [28, 29].

According to our experimental analysis, the sample tissues extracted from OPLL and non-OPLL patients showed a significant difference in their structure and components. Histological analysis of the sample tissue from the OPLL showed an ectopic formation of cartilaginous tissue with a proliferation of mature osteoblast-like cell. Based on our experimentation, we have demonstrated that the glucocorticoid dexamethasone can induce ectopic formation of cartilaginous tissue and growth of mature osteoblast-like cell. However, this induction can be inhibited when the Connexin 43-siRNA was transfected. Thus, we can further confirm that Connexin 43 can significantly moderate osteogenic differentiation under specific circumstances. This study further evaluated Connexin 43 and confirmed its effect on ERK activity in correlation to Runx2 modification. These results were also accordance with other studies [10, 30-32].

Protein and mRNA expression of OCN, ALP, COL I and Hcs24 were increased in OPLL tissue, leading to a confirmation that the tissue derived from OPLL had an osteogenic characteristic. In dexamethasone-induced cells, it was observed that the mRNA and protein expression of osseous genes were also increased. The Connexin 43 silencing system was designed to further assess our hypothesis and to observe whether inhibition of Connexin 43 can affect osteogenic differentiation in posterior longitudinal ligament cells. By performing this experiment, we proved that targeting Connexin 43 could be a leading factor for a therapeutic intervention towards OPLL. siRNA-Connexin 43 can cause significantly down regulated expressions of OCN, ALP, COL I and Hcs24 in posterior longitudinal ligament cells 72 hours after transfection. This result showed a further confirmation of our hypothesis.

Evaluation of ERK activity was performed in order to understand the correlation of Connexin 43 to Runx2. There was a significant down regulation of phospho-ERK activity during Connexin 43 inhibition, as well as a significantly decreased luciferase activity under Connexin 43 silencing system. ERK activity is directly proportional to Runx2 activity, leading to a down regulatory effect in the Connexin 43 silencing system [33]. To finalize our assessment, ERK inhibitor U-0126 was used to observe how ERK affects Runx2. ERK inhibitor U0126 caused a significant decrease in Runx2 activity, and decreased expression of bony genes ALP, OCN and COL1.

In addition to Connexin 43 functioning as a conduit for necessary intercellular exchange of ions, metabolites, second messengers, Connexin 43 is also required during osteogenic differentiation according to our analytical experiments. Furthermore, Connexin 43 has the ability to amplify the transcriptional activity of Runx2 by increasing ERK signals, and thus stimulate the osteoblast gene expression. These findings are consistent with a recent study in osteoblast cells in which the Connexin 43 enhances cell signaling and gene expression in osteoblast-like cells. The loss of Connexin 43 can impact the osteogenic differentiation of bones. However, dexamethasone-induction leads to a down regulation of osteogenic activity. The reduction of Connexin 43 affects ERK, which results in the decreased transcriptional activity of Runx2, subsequently leading to an attenuated signal cascade. Taken together, Connexin 43 can be a major factor in certain bone diseases at the molecular level.

Various studies in many cell systems have shown that altering gap junctional communication or alteration of Connexin 43 influences signal transduction, gene expression, cell migration, and survival [33-36]. Moreover, the convergence of Connexin 43 on Runx2 and ERK may not be the only mechanism by which Connexin 43 influences bone cell function [35]. Indeed, we suggest a further molecular study on the specific mechanism of Runx2 and possible modification on the signaling cascade.

Based on our results, we can conclude that Connexin 43 could be a potential therapeutic intervention related to ossification of posterior longitudinal ligament disease. We have 


\section{Cellular Physiology Cell Physiol Biochem 2016;38:237-247

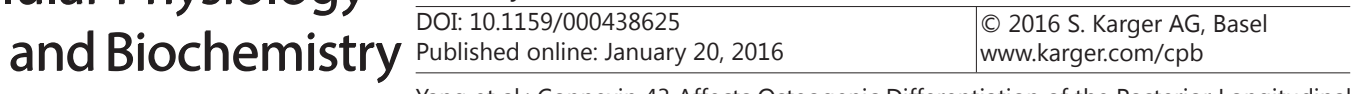 \\ Yang et al.: Connexin 43 Affects Osteogenic Differentiation of the Posterior Longitudinal Ligament Cells}

demonstrated that Connexin 43 can modify ERK activity and can regulate the activity of Runx2, leading to a significant effect on the osteogenic differentiation of the posterior longitudinal ligament.

\section{Acknowledgments}

This work was supported by the Young Scientists Fund of the National Nature Science Foundation of China (81201428).

\section{Disclosure Statement}

The authors have no conflict of interest.

\section{References}

1 Li JM, Zhang Y, Ren Y, Liu BG, Lin X, Yang J, Zhao HC, Wang YJ, Song L: Uniaxial cyclic stretch promotes osteogenic differentiation and synthesis of bmp2 in the c3h10t1/2 cells with bmp2 gene variant of rs2273073 (t/g). PLoS One 2014;9:e106598.

2 Zeinali M, Marandi HJ, Panahbekhoda MH, Mashari MA, Fallahpour S: Ossification of the posterior longitudinal ligament: A case report. Internet J Spine Surg 2009;5:203-207.

3 Choi BW, Song KJ, Chang H: Ossification of the posterior longitudinal ligament: A review of literature. Asian Spine J 2011;5:267-276.

4 Niger C, Luciotti MA, Buo AM, Hebert C, Ma V, Stains JP: The regulation of runt-related transcription factor 2 by fibroblast growth factor- 2 and connexin 43 requires the inositol polyphosphate/protein kinase cdelta cascade. J Bone Miner Res 2013;28:1468-1477.

5 Hills CE, Kerr MI, Wall MJ, Squires PE: Visfatin reduces gap junction mediated cell-to-cell communication in proximal tubule-derived epithelial cells. Cell Physiol Biochem 2013;32:1200-1212.

6 Chaible LM, Sanches DS, Cogliati B, Mennecier G, Dagli ML: Delayed osteoblastic differentiation and bone development in cx43 knockout mice. Toxicol Pathol 2011;39:1046-1055.

7 Solan JL, Lampe PD: Specific cx43 phosphorylation events regulate gap junction turnover in vivo. FEBS Lett 2014;588:1423-1429.

8 Plotkin LI, Speacht TL, Donahue HJ: Cx43 and mechanotransduction in bone. Curr Osteoporos Rep 2015;13:67-72.

9 Stains JP, Watkins MP, Grimston SK, Hebert C, Civitelli R: Molecular mechanisms of osteoblast/osteocyte regulation by connexin43. Calcif Tissue Int 2014;94:55-67.

10 Niger C, Buo AM, Hebert C, Duggan BT, Williams MS, Stains JP: Erk acts in parallel to pkcdelta to mediate the connexin43-dependent potentiation of runx2 activity by fgf2 in mc3t3 osteoblasts. Am J Physiol Cell Physiol 2012;302:C1035-1044.

11 Komori T, Kishimoto T: Cbfa1 in bone development. Curr Opin Genet Dev 1998;8:494-499.

12 Ueta C, Iwamoto M, Kanatani N, Yoshida C, Liu Y, Enomoto-Iwamoto M, Ohmori T, Enomoto H, Nakata K, Takada K, Kurisu K, Komori T: Skeletal malformations caused by overexpression of cbfa1 or its dominant negative form in chondrocytes. J Cell Biol 2001;153:87-100.

13 Boudenot A, Presle N, Uzbekov R, Toumi H, Pallu S, Lespessailles E: Effect of interval-training exercise on subchondral bone in a chemically-induced osteoarthritis model. Osteoarthritis Cartilage 2014;22:11761185.

14 Kim SM, Kim YG, Park JW, Lee JM, Suh JY: The effects of dexamethasone on the apoptosis and osteogenic differentiation of human periodontal ligament cells. J Periodontal Implant Sci 2013;43:168-176.

15 Yuasa M, Yamada T, Taniyama T, Masaoka T, Xuetao W, Yoshii T, Horie M, Yasuda H, Uemura T, Okawa A, Sotome S: Dexamethasone enhances osteogenic differentiation of bone marrow- and muscle-derived stromal cells and augments ectopic bone formation induced by bone morphogenetic protein-2. PLoS One 2015;10:e0116462. 


\section{Cellular Physiology Cell Physiol Biochem 2016;38:237-247 \begin{tabular}{ll|l} 
and Biochemistry & $\begin{array}{l}\text { DOI: 10.1159/000438625 } \\
\text { Published online: January 20, } 2016\end{array}$ & $\begin{array}{l}\text { C 2016 S. Karger AG, Basel } \\
\text { www.karger.com/cpb }\end{array}$ \\
\cline { 2 - 3 }
\end{tabular} \\ Yang et al.: Connexin 43 Affects Osteogenic Differentiation of the Posterior Longitudina
Ligament Cells}

16 Ghali O, Broux O, Falgayrac G, Haren N, van Leeuwen JP, Penel G, Hardouin P, Chauveau C: Dexamethasone in osteogenic medium strongly induces adipocyte differentiation of mouse bone marrow stromal cells and increases osteoblast differentiation. BMC Cell Biol 2015;16:9.

17 Tsukamoto N, Maeda T, Miura H, Jingushi S, Hosokawa A, Harimaya K, Higaki H, Kurata K, Iwamoto Y: Repetitive tensile stress to rat caudal vertebrae inducing cartilage formation in the spinal ligaments: A possible role of mechanical stress in the development of ossification of the spinal ligaments. J Neurosurg Spine 2006;5:234-242.

18 Uchida K, Yayama T, Sugita D, Nakajima H, Rodriguez Guerrero A, Watanabe S, Roberts S, Johnson WE, Baba $\mathrm{H}$ : Initiation and progression of ossification of the posterior longitudinal ligament of the cervical spine in the hereditary spinal hyperostotic mouse (twy/twy). Eur Spine J 2012;21:149-155.

19 Ishida Y, Kawai S: Characterization of cultured cells derived from ossification of the posterior longitudinal ligament of the spine. Bone 1993;14:85-91.

20 Contreras JE, Saez JC, Bukauskas FF, Bennett MV: Gating and regulation of connexin 43 (cx43) hemichannels. Proc Natl Acad Sci USA 2003;100:11388-11393.

21 Gago-Fuentes R, Carpintero-Fernandez P, Goldring MB, Brink PR, Mayan MD, Blanco FJ: Biochemical evidence for gap junctions and cx43 expression in immortalized human chondrocyte cell line: A potential model in the study of cell communication in human chondrocytes. Osteoarthritis Cartilage 2014;22:586590.

22 Civitelli R: Cell-cell communication in the osteoblast/osteocyte lineage. Arch Biochem Biophys 2008;473:188-192.

23 Rossello RA, H D: Cell communication and tissue engineering. Commun Integr Biol 2010;3:53-56.

24 Procaccia S, Kraus S, Seger R: Determination of erk activity: Anti-phospho-erk antibodies and in vitro phosphorylation. Methods Mol Biol 2010;661:39-58.

25 Jun JH, Yoon WJ, Seo SB, Woo KM, Kim GS, Ryoo HM, Baek JH: Bmp2-activated erk/map kinase stabilizes runx2 by increasing p300 levels and histone acetyltransferase activity. J Biol Chem 2010;285:36410-36419.

26 Shaul YD, Seger R: The mek/erk cascade: From signaling specificity to diverse functions. Biochim Biophys Acta 2007;1773:1213-1226.

27 McCubrey JA, Steelman LS, Chappell WH, Abrams SL, Wong EW, Chang F, Lehmann B, Terrian DM, Milella M, Tafuri A, Stivala F, Libra M, Basecke J, Evangelisti C, Martelli AM, Franklin RA: Roles of the raf/mek/ erk pathway in cell growth, malignant transformation and drug resistance. Biochim Biophys Acta 2007;1773:1263-1284.

28 Epstein N: Ossification of the cervical posterior longitudinal ligament: A review. Neurosurg Focus 2002;13:ECP1.

29 Furushima K, Shimo-Onoda K, Maeda S, Nobukuni T, Ikari K, Koga H, Komiya S, Nakajima T, Harata S, Inoue I: Large-scale screening for candidate genes of ossification of the posterior longitudinal ligament of the spine. J Bone Miner Res 2002;17:128-137.

30 Batra N, Kar R, Jiang JX: Gap junctions and hemichannels in signal transmission, function and development of bone. Biochim Biophys Acta 2012;1818:1909-1918.

31 Paznekas WA, Karczeski B, Vermeer S, Lowry RB, Delatycki M, Laurence F, Koivisto PA, Van Maldergem L, Boyadjiev SA, Bodurtha JN, Jabs EW: Gja1 mutations, variants, and connexin 43 dysfunction as it relates to the oculodentodigital dysplasia phenotype. Hum Mutat 2009;30:724-733.

32 Lima F, Niger C, Hebert C, Stains JP: Connexin43 potentiates osteoblast responsiveness to fibroblast growth factor 2 via a protein kinase c-delta/runx2-dependent mechanism. Mol Biol Cell 2009;20:2697-2708.

33 Yang HS, Lu XH, Chen DY, Yuan W, Yang LL, He HL, Chen Y: Upregulated expression of connexin43 in spinal ligament fibroblasts derived from patients presenting ossification of the posterior longitudinal ligament. Spine (Phila Pa 1976) 2011;36:2267-2274.

34 Niger C, Lima F, Yoo DJ, Gupta RR, Buo AM, Hebert C, Stains JP: The transcriptional activity of osterix requires the recruitment of sp1 to the osteocalcin proximal promoter. Bone 2011;49:683-692.

35 Hebert C, Stains JP: An intact connexin43 is required to enhance signaling and gene expression in osteoblast-like cells. J Cell Biochem 2013;114:2542-2550.

36 Civitelli R, Beyer EC, Warlow PM, Robertson AJ, Geist ST, Steinberg TH: Connexin43 mediates direct intercellular communication in human osteoblastic cell networks. J Clin Invest 1993;91:1888-1896. 